\title{
Simultaneous Quantification of Mitochondrial DNA Damage and Copy Number in Circulating Blood: A Sensitive Approach to Systemic Oxidative Stress
}

\author{
Sam W. Chan, Simone Chevalier, Armen Aprikian, and Junjian Z. Chen \\ Department of Surgery/Division of Urology, The Research Institute of McGill University Health Center, 1650 Cedar Avenue, \\ Room R1.107, Montreal, QC, Canada H3G 1 A4
}

Correspondence should be addressed to Junjian Z. Chen; junjian.chen@mcgill.ca

Received 2 September 2012; Revised 12 November 2012; Accepted 13 November 2012

Academic Editor: Gurmit Singh

Copyright (c) 2013 Sam W. Chan et al. This is an open access article distributed under the Creative Commons Attribution License, which permits unrestricted use, distribution, and reproduction in any medium, provided the original work is properly cited.

Systemic oxidative stress is associated with a wide range of pathological conditions. Oxidative DNA damage is frequently measured in circulating lymphocytes. Mitochondrial DNA (mtDNA) is known to be more sensitive to oxidative damage than nuclear DNA but is rarely used for direct measurement of DNA damage in clinical studies. Based on the supercoiling-sensitive real-time PCR method, we propose a new approach for the noninvasive monitoring of systemic oxidative stress by quantifying the mtDNA structural damage and copy number change in isolated lymphocytes in a single test. We show that lymphocytes have significantly less mtDNA content and relatively lower baseline levels of damage than cancer cell lines. In an ex vivo challenge experiment, we demonstrate, for the first time, that exogenous $\mathrm{H}_{2} \mathrm{O}_{2}$ induces a significant increase in mtDNA damage in lymphocytes from healthy individuals, but no repair activity is observed after $1 \mathrm{~h}$ recovery. We further demonstrate that whole blood may serve as a convenient alternative to the isolated lymphocytes in mtDNA analysis. Thus, the blood analysis with the multiple mtDNA end-points proposed in the current study may provide a simple and sensitive test to interrogate the nature and extent of systemic oxidative stress for a broad spectrum of clinical investigations.

\section{Introduction}

Oxidative stress is a state of physiological imbalance between oxidant production and antioxidant defence at different biological levels. It is implicated in the development of many pathological conditions such as aging, neurodegenerative diseases, and cancer initiation and progression [1-6]. Many diseases are suspected to be linked to oxidative stress, but procurement of disease tissues may be difficult due to its invasive nature and the scarcity of available tissues. However, researchers have mitigated this problem by using the systemic oxidative stress in peripheral tissues, such as circulating blood, as a noninvasive surrogate. Extrinsic factors such as inflammation, nutrient imbalance, and hypoxic environment could affect inter and intracellular redox homeostasis, therefore altering systemic oxidative stress levels; new efforts are made to investigate the interactions between systemic oxidative stress and pathogenesis of many disease conditions [7-13]. For example, several recent studies suggest a correlation between increased systemic oxidative stress and prostate cancer risk and progression [14-16]. Similar results are reported in lung cancer [17], head and neck cancer [18], and other human cancers $[19,20]$. Thus, enhanced oxidative stress is not only a common property of the diseased cells, but may also be reflected in the peripheral tissues.

Systemic oxidative stress has been analyzed in serum and blood cells using different biomarkers and assay systems. Genomic DNA in circulating lymphocytes is a widely used target in measuring different end-points of oxidative DNA damage, such as 8-oxoguanine (8-oxo-G) base lesions or DNA strand breaks detected with the comet assay [14-18]. The mitochondrial DNA (mtDNA) in lymphocytes is an attractive alternative target to determine systemic oxidative stress. MtDNA is a circular, multicopy cytoplasmic DNA, 
semiautonomously maintained in mitochondria. It is known to be more sensitive to oxidative damage than nuclear DNA [21-23] and has been increasingly used for evaluating systemic oxidative stress with various assays. Similarly to nuclear DNA, 8-oxo-G base lesions can be assessed in purified mtDNA from lymphocytes [24]. Extracellular circulating mtDNA in serum is another marker recently used for evaluating genetic integrity and cancer risk. Elevated levels of free floating mtDNA detected in the plasma or serum are found to be associated with poor prognoses for prostate and testicular germ cell cancers [25-27]. However, the source and nature of this circulating mtDNA are not fully elucidated. Oxidative stress can also affect the total mtDNA content in lymphocytes under various diseased conditions [28]. For example, significant alterations in mtDNA content were detected in lymphocytes from patients with renal cell carcinoma, hyperlipidemia, and Huntington's disease when compared to control populations $[19,29,30]$. However, the relationship between different mtDNA end-points reported in lymphocytes is not clear and the direct measurement of mtDNA strand breaks in lymphocytes has not been reported. We previously developed a sensitive in vitro assay to quantify mtDNA structural damage induced by strand breaks, repair and copy number change in prostate cancer cell lines using a supercoiling-sensitive real-time PCR (ss-qPCR) [6, 31]. We showed that oxidative damage can induce single- or doublestrand breaks (SSB or DSB), which lead to the disruption of the supercoiled conformation, and that the resulting relaxed conformation is a better qPCR substrate for significantly increased amplification than the supercoiled conformation, even if the starting mtDNA molecules remain the same [31]. Additionally, we observed that prolonged exposure to $95^{\circ} \mathrm{C}$ heat also introduced strand breaks in the mtDNA. This particular property was advantageously used to disrupt all structural features of mtDNA for precise quantification of the total mtDNA content [31].

The objectives of this current study were to test if the ssqPCR method could be applied to the lymphocytes and to explore a quantitative strategy to measure multiple mtDNA end-points in circulating blood cells for the study of systemic oxidative stress. We developed an absolute quantification method for precise measurement of mtDNA structural damage, copy number change, and repair activity in blood cells. We demonstrated that mtDNA has low levels of both copy number and baseline damage in lymphocytes as compared to cancer cell lines, and that exogenous $\mathrm{H}_{2} \mathrm{O}_{2}$ led to a significant increase in mtDNA damage but with little repair activity in inactivated lymphocytes in ex vivo experiments.

\section{Materials and Methods}

2.1. Chemicals, Reagents, and Cell Culture. All chemicals were purchased from Sigma-Aldrich (Oakville, ON, Canada) unless otherwise specified. Prostate cancer cell line LNCaP was purchased from ATCC (Manassas, VA). C4-2, a gift from Dr. L.W.K. Chung, is an isogenic clone of the LNCaP cell line with increased invasive potential [32]. LNCaP and C42 prostate cancer cells were cultured in RPMI 1640 complete medium (Invitrogen, Burlington, Ontario, Canada) supplemented with $10 \%$ fetal bovine serum (FBS) (Invitrogen) and $1 \%$ penicillin-streptomycin (Invitrogen). LNCaP cells were cultured in Poly-L-Lysine (1\%) coated dishes. The cells were collected with a Trypsin/EDTA solution, (0.05\% trypsin + $0.02 \%$ EDTA) then washed down with PBS and stored at $-80^{\circ} \mathrm{C}$.

2.2. Blood Collection and Lymphocyte Preparation. Healthy male volunteers ranging from 28 to 45 years old were recruited for this pilot study through an institutional review board (REB) approved protocol at the McGill University Health Center. Blood (10 to $15 \mathrm{~mL}$ ) was collected into $9 \mathrm{~mL}$ collection tubes coated with EDTA (Vacu K3EDTA PULL LAV) (Fisher, Monroe, NC). For experiments with whole blood, the samples were immediately stored at $-80^{\circ} \mathrm{C}$ in $10 \%$ dimethyl sulfoxide (DMSO) prior to analysis. For experiments with isolated lymphocytes, blood was submitted to Ficoll-Paque Plus (GE Healthcare, Buckinghamshire, England) to recover the lymphocytes [33], then stored at $-80^{\circ} \mathrm{C}$ in 40\% RPMI media 1640 supplemented with 50\% FBS and 10\% DMSO prior to analysis. As per manufacturer's specifications, the extracted sample is composed in majority of lymphocytes (75-93\%), with a remaining fraction of monocytes (7-25\%) and minimal contaminants from granulocytes, erythrocytes, and platelets ( $3 \pm 2 \%, 5 \pm 2 \%$, and $<0.5 \%$, resp.).

2.3. $\mathrm{H}_{2} \mathrm{O}_{2}$ Challenge Experiments with Lymphocytes and Whole Blood. Frozen lymphocytes were thawed in a $37^{\circ} \mathrm{C}$ water bath for 1-2 min and washed with 5 volumes of icecold wash medium (50\% FBS and 50\% RPMI 1640). The lymphocytes were counted and cell viability was assessed under microscope using the trypan blue dye (average of over $90 \%$ viability). A total of $\sim 3 \times 10^{6}$ lymphocytes were incubated in $50 \mathrm{~mL}$ conical tubes with RPMI-1640 complete medium for $30 \mathrm{~min}$ prior to the experiment. The cell suspension was split into three groups of $\sim 1 \times 10^{6}$ cells each, treated with 0 (control) or $120 \mu \mathrm{M} \mathrm{H}_{2} \mathrm{O}_{2}$ for $15 \mathrm{~min}$ for exposure or allowed to recover in fresh medium for $60 \mathrm{~min}$. The concentration of $120 \mu \mathrm{M} \mathrm{H}_{2} \mathrm{O}_{2}$ was chosen to be in the lower-middle range of concentrations used in similar treatments in the literature (50 to $500 \mu \mathrm{M})[14,34]$. Afterwards, the lymphocyte samples were washed with PBS, spun down to a pellet, and then stored at $-80^{\circ} \mathrm{C}$ before DNA preparation.

Frozen whole blood was thawed in a $37^{\circ} \mathrm{C}$ water bath for 1-2 min and washed with 5 volumes of ice-cold PBS wash medium. The whole blood cells were counted with trypan blue dye prior to incubation (average of over $90 \%$ viability). A total of $\sim 15 \times 10^{6}$ whole blood cells were incubated in RPMI1640 complete medium in $50 \mathrm{~mL}$ conical tubes for $30 \mathrm{~min}$ prior to the experiment. Whole blood samples were separated into three groups with $\sim 5 \times 10^{6}$ cells each and treated with 0 or $120 \mu \mathrm{M} \mathrm{H}_{2} \mathrm{O}_{2}$ as in the lymphocyte experiment. Whole blood samples were collected after treatment and stored at $-80^{\circ} \mathrm{C}$ before DNA preparation.

2.4. DNA Preparation for the ss-qPCR Analysis. DNA was extracted with the QIAGEN Blood \& Cell Culture DNA 
TABle 1: Primer sequences.

\begin{tabular}{lll}
\hline Primers & Forward $5^{\prime}-3^{\prime}$ & Reverse $5^{\prime}-3$ \\
\hline CO2 3285 bp long fragment & CCTAGGGTTTATCGTGTGAG & CTAGTTAATGGAAGTTAACGG \\
D-loop 2467 bp long fragment & CGCACGGACTACAACCACGAC & CTGTGGGGGGTGTCTTTGGGG \\
Calicin 2658 bp long fragment & ATTCCAGAAGCCTTTAACTAG & ACAAATGAGACACAAACTACCG \\
CO2 (for real-time PCR) & CCCCACATTAGGCTTAAAAACAGAT & TATACCCCCGGTCGTGTAGCGGT \\
D-loop (for real-time PCR) & TATCTTTTGGCGGTATGCACTTTTAACAGT & TGATGAGATTAGTAGTATGGGAGTGG \\
Calicin (for real-time PCR) & CTGGTCGCTACATCTACATCTC & CAGGTCAGGCAACTTGGTC \\
\hline
\end{tabular}

Kit according to the manufacturer's instructions with minor modifications to ensure that both mtDNA and nuclear DNA were collected together $[31,35]$. Total DNA was quantified with a NanoDrop spectrophotometer. DNA template solutions of $1 \mathrm{ng} / \mu \mathrm{L}$ were prepared for each sample with $1 \mathrm{X}$ Tris/EDTA Buffer Solution ( $\mathrm{pH}$ 8.0). Each template solution was split into two equal parts with half serving as an original template for the measurement of the damaged/relaxed mtDNA fraction and the other half heat-treated $\left(95^{\circ} \mathrm{C}\right.$ for 6 min on a PCR machine) to quantify total amount of mtDNA [31].

2.5. Nuclear DNA and mtDNA Standards Preparation for Absolute Quantification. MtDNA standards were prepared for absolute quantification. A $3.3 \mathrm{~kb} \mathrm{mtDNA}$ fragment containing the $\mathrm{CO} 2$ gene and a $2.5 \mathrm{~kb}$ fragment containing the D-loop region were amplified from the immortalized normal human prostate cell line, RWPE-1, using primers listed in Table 1. PCR reactions were performed using the GeneAmp PCR 9700 system (ABI) with recombinant Thermus thermophilus (rTth) DNA polymerase (ABI). The amplification program was performed as follows: preheat samples to reach $75^{\circ} \mathrm{C}$; add rTth DNA polymerase and incubate for $2 \mathrm{~min}$; denature at $94^{\circ} \mathrm{C}$ for $1 \mathrm{~min}$, followed by 30 cycles of $94^{\circ} \mathrm{C}$ for $15 \mathrm{sec}, 60^{\circ} \mathrm{C}$ for $30 \mathrm{sec}$, and $72^{\circ} \mathrm{C}$ for $3.5 \mathrm{~min}$; then $72^{\circ} \mathrm{C}$ for $5 \mathrm{~min}$ and cool down to $10^{\circ} \mathrm{C}$. Amplified DNA fragments were purified with the QIAGEN PCR Purification Kit. The purified products were carefully quantified with the Nanodrop spectrophotometer, and the average of three readings was used for calculating precise copy number according to the following equation (Figure 1):

$$
\text { copies } / \mu \mathrm{L}=\frac{[\mathrm{ng} / \mu \mathrm{L}]}{\mathrm{m}} \text {. }
$$

Six or seven serial dilutions were made ranging from $3 \times$ $10^{6}$ to 30 or $3 \times 10^{7}$ to 30 copies with a dilution factor of 10 depending on the experiment. The 6-point standard was used for the mtDNA quantification in blood samples, while the 7-point standard was used to demonstrate the dynamic range and linearity of the assay. The original stock solutions were made into small aliquots and stored at $-80^{\circ} \mathrm{C}$ to prevent repeated freeze and thaw.

The nuclear DNA standards were similarly prepared. The nuclear primer sequences are listed in Table 1 . A $2.7 \mathrm{~kb}$ nuclear fragment containing the calicin gene was amplified from RWPE-1. Calicin is a single-copy nuclear gene that encodes for a basic protein of the sperm head cytoskeleton.
2.6. Quantification of mtDNA Damage and Copy Number Using the Absolute ss-qPCR Method. The amount of relaxed/damaged $\mathrm{mtDNA}$ and total copy number were measured by quantifying the original and preheated DNA templates, respectively. The nuclear DNA marker calicin was quantified using the original templates. The qPCR was performed using the Applied Biosystems7500 Fast RealTime PCR System (ABI) with Power SYBR Fast Green PCR MASTER MIX (ABI) [35]. The original DNA templates and preheated DNA templates and standards were analyzed in triplicates on the same plate. The two-step PCR amplification program for both nuclear DNA and mtDNA was $95.0^{\circ} \mathrm{C}$ for $30 \mathrm{sec}$, followed by 40 cycles of $95.0^{\circ} \mathrm{C}$ for $3 \mathrm{sec}$ and $60.0^{\circ} \mathrm{C}$ for $30 \mathrm{sec}$. A melt curve analysis was enabled at the end of amplification. The primer sequences are listed in Table 1. The absolute copy numbers of CO2, D-loop, and calicin were calculated based on the standard curves. Since calicin is a single copy nuclear gene, the cell number could be calculated with the following equation with the assumption that the nuclear equivalent is representative of the cell number (Figure $1)$ :

Cell number or nuclear equivalent

$$
=\frac{\text { Calicin copy number }}{\text { ploidy of cell }} \text {. }
$$

The exact copies of damaged and total mtDNA per cell were calculated from:

$$
\frac{\mathrm{mtDNAcopies}}{\text { cell }}=\frac{\mathrm{CO} 2 \text { or D-Loop copy number }}{\text { cell number }} \text { } \text {, }
$$

* cell number and nuclear equivalent will be used interchangeably from this point.

2.7. Data Analysis. All statistical analyses were performed with the aid of Graphpad Prism version 4 software. Unless specified otherwise, the data was analyzed with one-way ANOVA with Dunnett post test, and a $P<0.05$ is considered significant.

\section{Results}

3.1. A New Strategy for the Absolute Quantification of Total and Damaged mtDNA. We have devised a new approach for the absolute quantification of mtDNA structural damage and total copy number in a single analysis. The protocol, illustrated in Figure 1, was comprised of four main steps. 
(a)

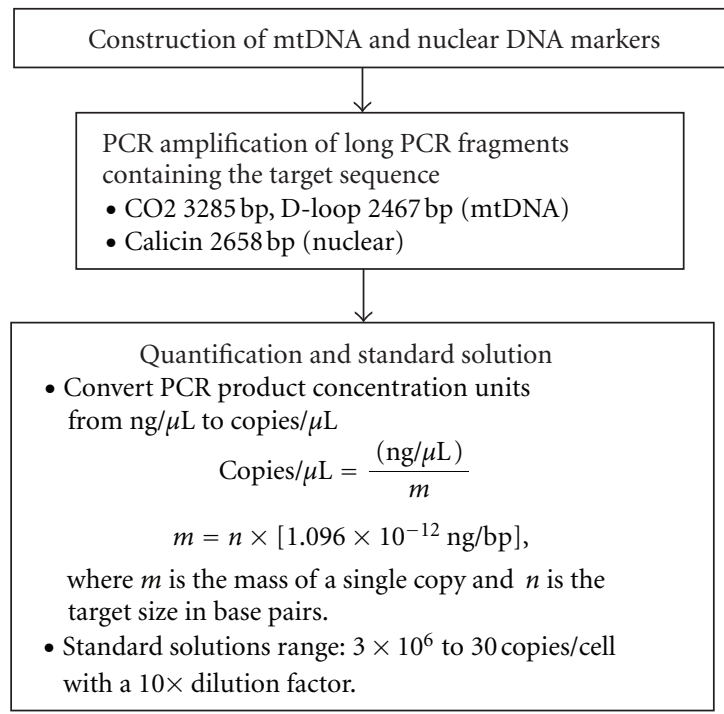

(b)

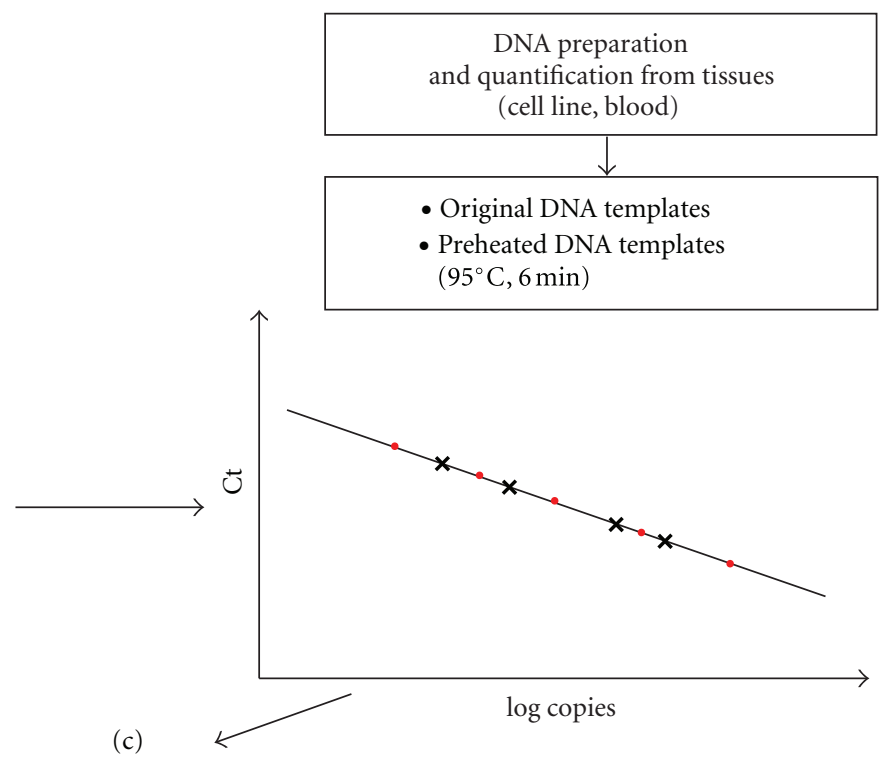

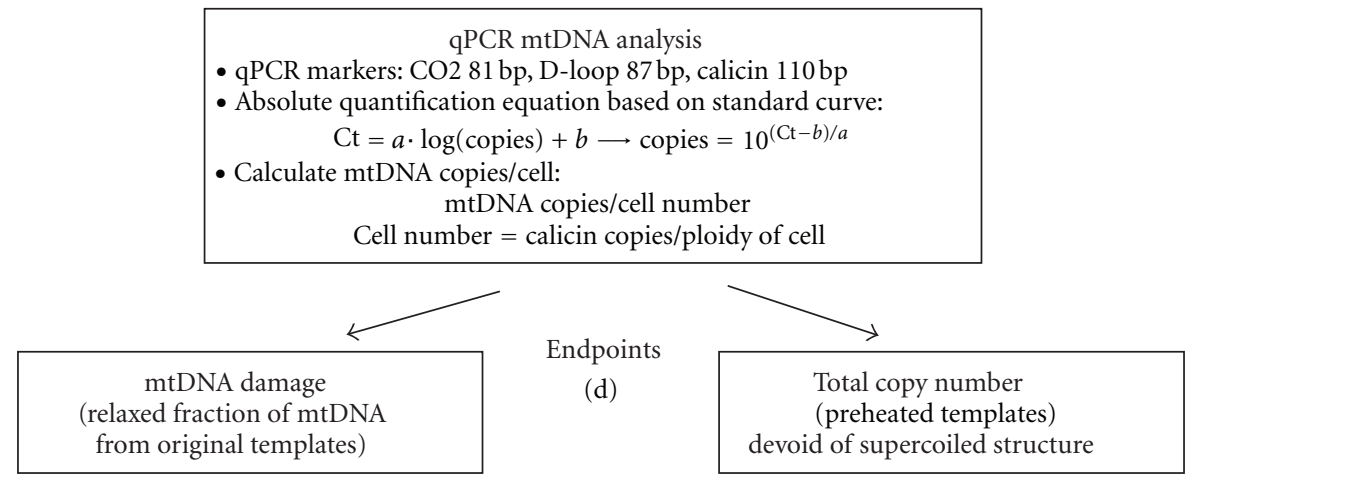

FIGURE 1: A new strategy for absolute quantification of total and damaged mtDNA. This protocol is separated into four main steps. (a) Construction of the mtDNA and nuclear DNA standards. Long fragments of genes that contained the shorter real-time PCR targets were amplified and a 10X serial dilution was made from $3 \times 10^{6}$ to 30 copies. (b) Preparation of the original and preheated DNA templates from lymphocytes DNA samples for the analysis of mtDNA damage and total mtDNA, respectively. (c) Real-time PCR absolute quantification analysis of mtDNA damage and total content. (d) Interpretation of the data.

The first step consisted in the construction of mtDNA and nuclear DNA standards (Figure 1(a)). Two to three kb DNA fragments containing mtDNA (CO2 or D-loop) and nuclear DNA (calicin) were amplified by PCR from a normal prostate cell line, RWPE-1. The concentration (copies/ $\mu \mathrm{L}$ ) of these long DNA fragments were quantified and calculated according to (1). The second step was to prepare the DNA templates for qPCR analysis (Figure 1(b)). Each DNA template was split into two equal halves. One half was used for the quantification of relaxed mtDNA and calicin nuclear DNA copies. The other half was pretreated at $95^{\circ} \mathrm{C}$ for 6 min to unfold any structure and was used for quantifying total mtDNA. The third step consisted in the absolute quantification using qPCR (Figure 1(c)). To obtain mtDNA content per cell, the exact amount of mtDNA and nuclear DNA copies were quantified and calculated from the standard curves according to the equation: copies $=$ " $10^{(\mathrm{Ct}-b) / a}$," where the cell number was derived from (2). The final step was the interpretation of the data (Figure 1(d)). With this approach, the amount of damaged mtDNA copies/cell, total mtDNA copies/cell, and baseline mtDNA damage (ratio of damaged mtDNA/total mtDNA) were quantified simultaneously.

3.2. Dynamic Range, Linearity, Specificity, and Reproducibility of DNA Markers. The standard curve and the melting curve for CO2, D-loop, and calicin amplification were evaluated (Figure 2). Each data point was run in triplicates. The threshold cycles $(\mathrm{Ct})$ of CO2, D-loop, and calicin amplification were based on 10X serially diluted standards ranging from $3 \times 10^{7}$ to 30 copies and were shown in Figures 2(a), 2(c), and 2(e). The PCR amplification efficiencies were 95.8\%, 95.7\%, and 95.4\% for CO2, D-loop, and calicin, respectively. Linearity of the standard curve amplification was maintained in the dynamic range of 10 to $10^{7}$ since the $R$-values of linear regression lines were 0.9998 for $\mathrm{CO} 2,0.9988$ for $\mathrm{D}$-loop, and 


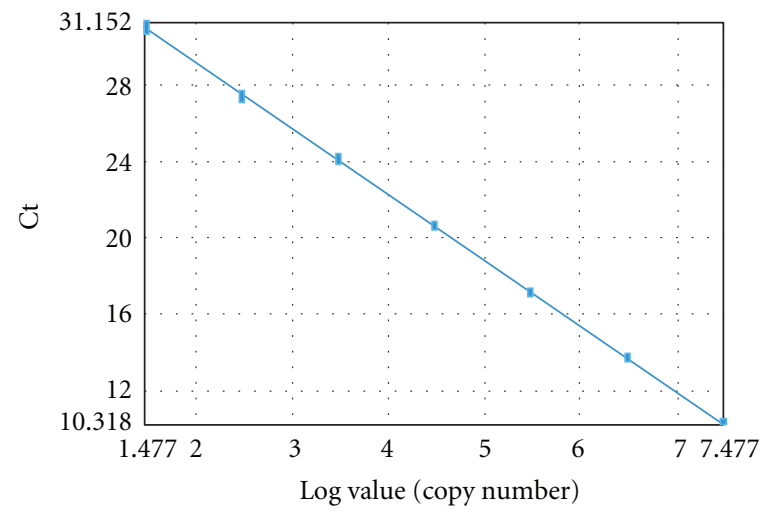

(a)

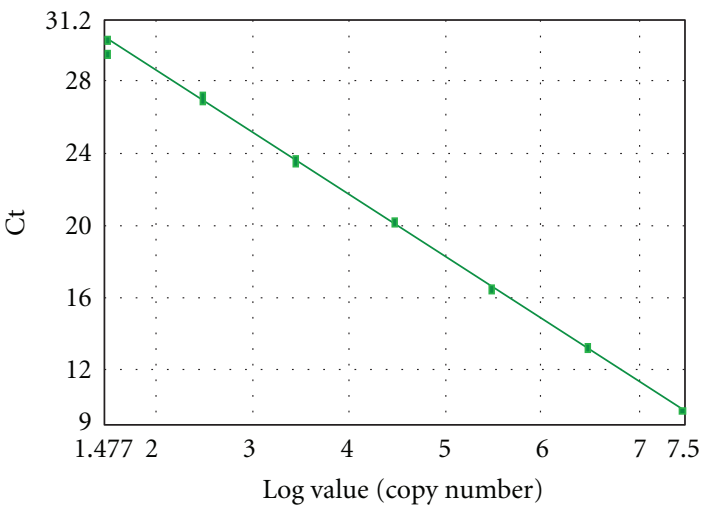

(c)

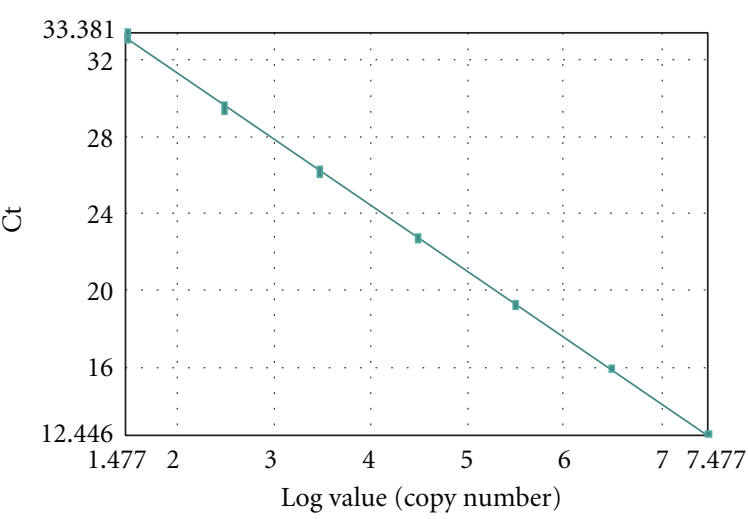

(e)

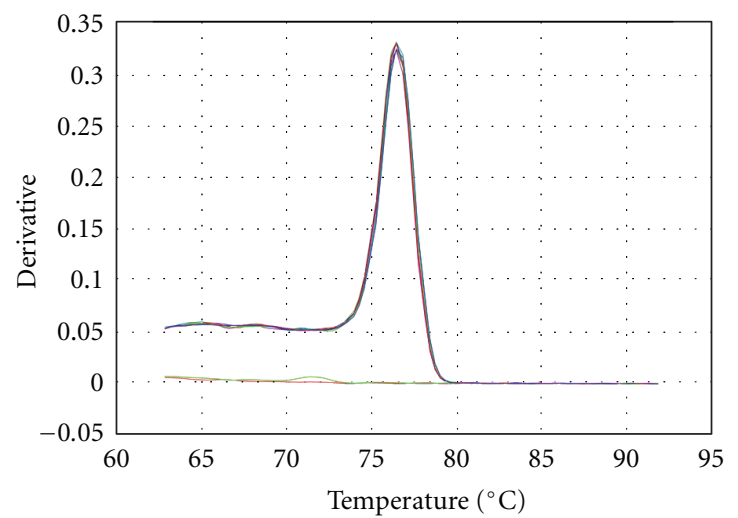

(b)

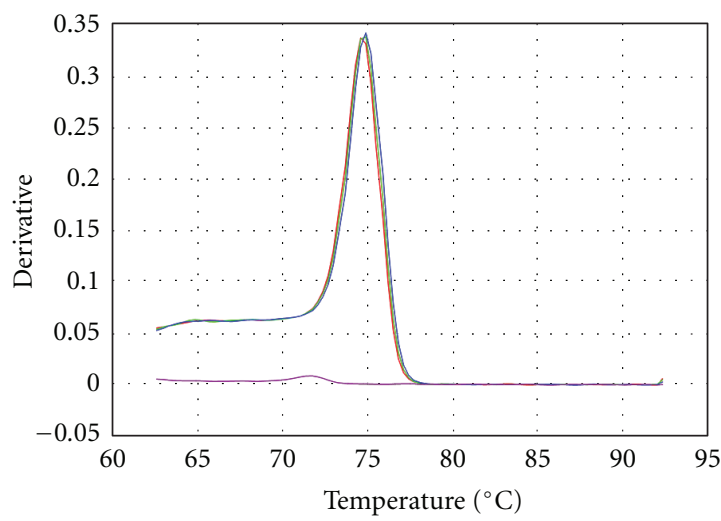

(d)

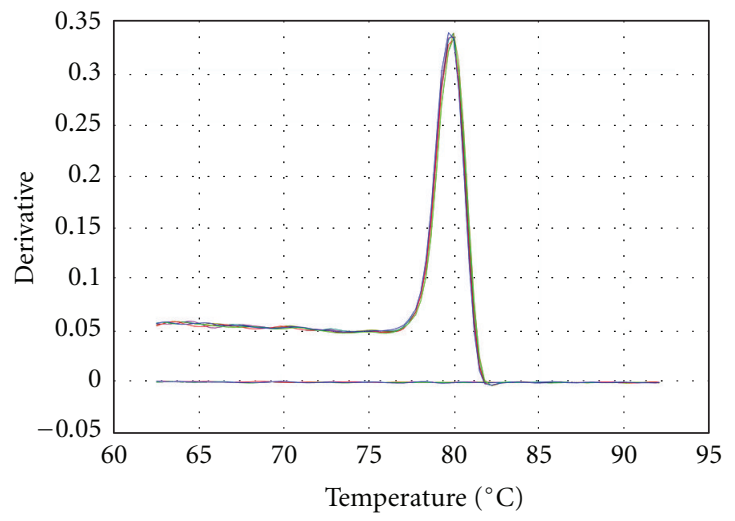

(f)

FIGURE 2: Dynamic range, linearity, specificity, and reproducibility. QPCR amplification of 7-point standard curves from $3 \times 10^{7}$ to 30 copies of (a) CO2, (c) D-loop, and (e) calicin markers. Melting curves showing the negative first derivative of the fluorescence signal of (b) CO2, (d) D-loop, and (f) calicin PCR product.

0.9996 for calicin. A single uniform melting peak at $76^{\circ} \mathrm{C}$, $75^{\circ} \mathrm{C}$, and $79^{\circ} \mathrm{C}$ was observed for CO2, D-loop, and calicin, respectively, demonstrating the high specificity of the primers (Figures 2(b), 2(d), and 2(f)). The intra-assay reproducibility of the standard was analyzed by calculating the coefficient of variation $(\mathrm{CV})$ of the triplicates. The intra-assay median $\mathrm{CV}$ were $0.27 \%, 0.17 \%$, and $0.12 \%$ for CO2, D-loop, and calicin, respectively (Table 2). The interassay $\mathrm{CV}$ was calculated with data from two or more independent experiments: the $\mathrm{CV}$ were $0.33 \%, 0.10 \%$, and $0.62 \%$ for CO2, D-loop, and calicin, respectively (Table 2). These low $\mathrm{CV}$ values demonstrated very high intra- and interassay reproducibility of these new DNA markers.

3.3. Total Absolute Quantification of mtDNA Content and Baseline mtDNA Damage in Lymphocytes and Prostate Cancer Cells. Lymphocyte samples and two isogenic prostate cancer 
TABLE 2: Intra- and interassay CV for standards.

\begin{tabular}{lcc}
\hline Standards & Intra-assay CV (\%) & Interassay CV (\%) \\
\hline \multirow{2}{*}{ CO2 } & 0.27 & 0.33 \\
& $(0.10-0.72)$ & $(0.11-0.80)$ \\
D-loop & 0.18 & 0.10 \\
& $(0.03-0.16)$ & $(0.05-0.78)$ \\
calicin & 0.12 & 0.62 \\
& $(0.02-0.67)$ & $(0.09-1.74)$ \\
\hline
\end{tabular}

Median CV value with CV range.

TABLE 3: Intra- and interassay CV for samples.

\begin{tabular}{lcc}
\hline Sample type & Intra-assay CV (\%) & Interassay CV (\%) \\
\hline Prostate cell & 0.74 & 1.20 \\
lines $^{*}$ & $(0.26-1.86)$ & $(0.68-1.85)$ \\
Lymphocytes & 1.87 & 2.33 \\
& $(1.18-2.51)$ & $(1.45-4.66)$ \\
\hline
\end{tabular}

Median CV value with CV range

${ }^{*}$ RWPE-1, C4-2, LNCaP, PC-3.

cell lines, LNCaP and C4-2, were analyzed for mtDNA content and baseline damage. The prostate cancer cell lines served a reference in method development because the ssqPCR method was previously developed with these cell lines $[6,31,35]$. In lymphocytes, the total mtDNA content was quantified at an average of $153.25 \pm 21.02$ copies/cell from 4 individual samples, among which the amount of damaged mtDNA molecules was averaged at $41.44 \pm 7.87$ copies/cell (Figure 3(a)). In comparison, significantly higher mtDNA contents were detected in prostate cancer cells C4-2 $(1495.35 \pm 12.45, P<0.01)$ and $\operatorname{LNCaP}(3086.61 \pm 48.27$, $P<0.01)$. The damaged mtDNA copies were $466.44 \pm$ 8.64 and $990.41 \pm 6.77$ copies/cell, respectively. The baseline damage was calculated with the ratio of damaged mtDNA over total mtDNA: $27.04 \%$ of the total mtDNA content was damaged for lymphocytes versus $31.19 \%$ and $32.09 \%$ for C4-2 and LNCaP, respectively (Figure 3(b)). This assay was highly reproducible; the median intra- and interassay CV were $0.74 \%$ and $1.20 \%$ for cell lines and $1.87 \%$ and $2.33 \%$ for lymphocytes, respectively (Table 3 ). Furthermore, the use of different mtDNA markers, $\mathrm{CO} 2$ and D-loop, generated near identical results in terms of total mtDNA content, damaged mtDNA, and baseline damage detected (Figure $3(\mathrm{c})$ ). Indeed, the average $\mathrm{CV}$ value obtained between $\mathrm{CO} 2$ and D-loop markers was calculated at $0.51 \%$. Thus, these two mtDNA markers were highly consistent and interchangeable in quantitative mtDNA analyses. It was interesting to note that the absolute number of damaged mtDNA molecules was proportionally higher in samples with increased total copy numbers (Figure 3(a)). As such, the ratio between damaged and total copy numbers was a better indicator of the baseline level of DNA damage in a cell (Figure 3(b)). Taken together, the new quantification platform developed in this study provided a highly reproducible method for simultaneous analysis of absolute mtDNA copy number, damaged molecules, and baseline damage in both isolated lymphocytes and cancer cell lines.
3.4. Ex Vivo mtDNA Damage Responses to Exogenous $\mathrm{H}_{2} \mathrm{O}_{2}$ in Isolated Lymphocytes and in Whole Blood. Isolated lymphocytes from 9 healthy men were treated with 0 or $120 \mu \mathrm{M} \mathrm{H}_{2} \mathrm{O}_{2}$ for $15 \mathrm{~min}$ to evaluate induced mtDNA damage and repair activity after $60 \mathrm{~min}$ of recovery. The average mtDNA copy number of the untreated control samples was $161.78 \pm 31.67$ copies/cell (Figure 4(a)). The total mtDNA copy number was not affected by $\mathrm{H}_{2} \mathrm{O}_{2}$ treatment and remained stable across all treatment groups (Figure 4(a)). However, rapid mtDNA damage response was observed. The average baseline damage of untreated control samples was 27.63\% (Figure 4(b)). Upon $\mathrm{H}_{2} \mathrm{O}_{2}$ exposure, the fraction of damaged mtDNA increased to $58.19 \%$ in lymphocytes, representing a $110.6 \%$ increase in induced damage from the control $(P<0.001)$. Interestingly, the induced damage was not repaired after 60 min of recovery, suggesting a lack of repair activity during the recovery period.

As an alternative to the isolated lymphocytes, a small amount of whole blood samples $(<1 \mathrm{~mL}$ each) from four healthy subjects was tested using the same procedure. The average total mtDNA content of untreated control was 109.4 \pm 22.40 copies/cell (Figure 5(a)). Similar to lymphocytes, the average baseline mtDNA damage of the untreated control samples was $26.6 \%$ (Figure 5(b)). When treated with $120 \mu \mathrm{M}$ $\mathrm{H}_{2} \mathrm{O}_{2}$, the damaged fraction of mtDNA increased to $36.7 \%$, representing a $38.0 \%$ increase in induced damage as compared to the baseline levels $(P<0.05)$, while the total mtDNA content remained the same (Figure 5(b)). An absence of repair activity was also observed within 60 min recovery after the $\mathrm{H}_{2} \mathrm{O}_{2}$ treatment. However, the whole blood samples had slightly lower mtDNA content and less pronounced mtDNA damage responses as compared to the lymphocytes. This could be caused by the complexity of different types of white blood cells present in whole blood samples. Despite this difference, the overall stress response pattern was similar between the isolated lymphocytes and the whole blood. Thus, the latter may serve as a convenient alternative to isolated lymphocytes in the analysis of mtDNA stress responses in circulating blood.

\section{Discussion}

Based on our previously developed ss-qPCR method [6, 31, 35], we propose a quantitative approach for precise and rapid detection of mtDNA structural damage and copy number change in isolated lymphocytes in a single analysis. We have demonstrated that the new approach had a wide dynamic range and was highly specific and reproducible. A relatively low mtDNA content and baseline level of damage were observed in lymphocytes of healthy men, and the lymphocytes were shown for the first time to exhibit a significant increase in mtDNA damage, followed by little repair activity after $1 \mathrm{~h}$ of recovery in an ex vivo challenge experiment with $\mathrm{H}_{2} \mathrm{O}_{2}$. This lack of repair activity to $\mathrm{H}_{2} \mathrm{O}_{2}$-induced damage after $1 \mathrm{~h}$ of recovery is consistent with a study from Collins et al. in which nuclear DNA repair activity was only observed after several hours ( $>2 \mathrm{~h}$ ) [34]. Moreover, we showed that $1 \mathrm{~mL}$ of whole blood may serve as a convenient alternative 


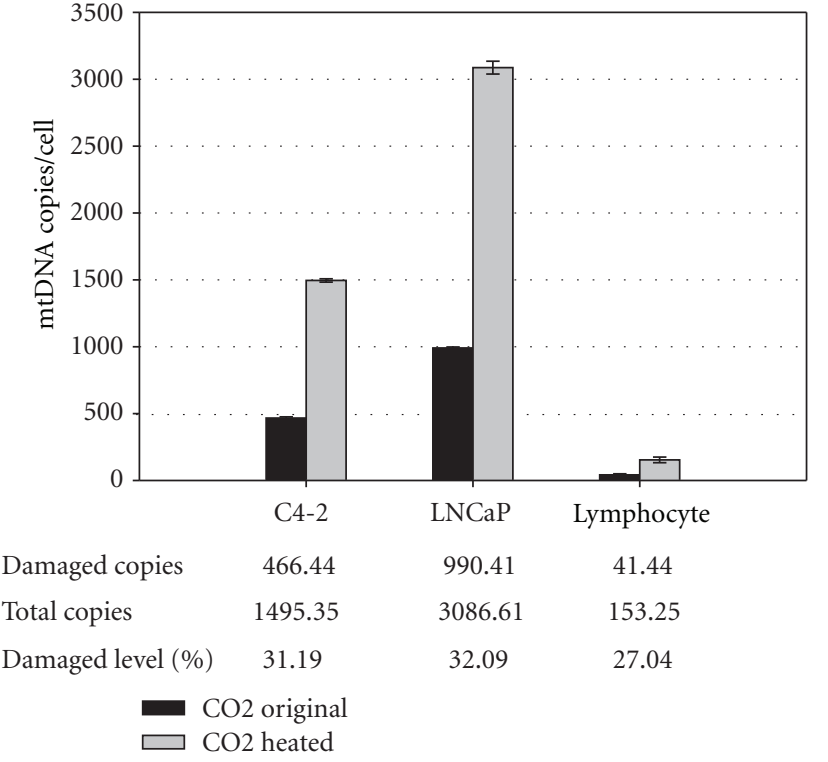

(a)

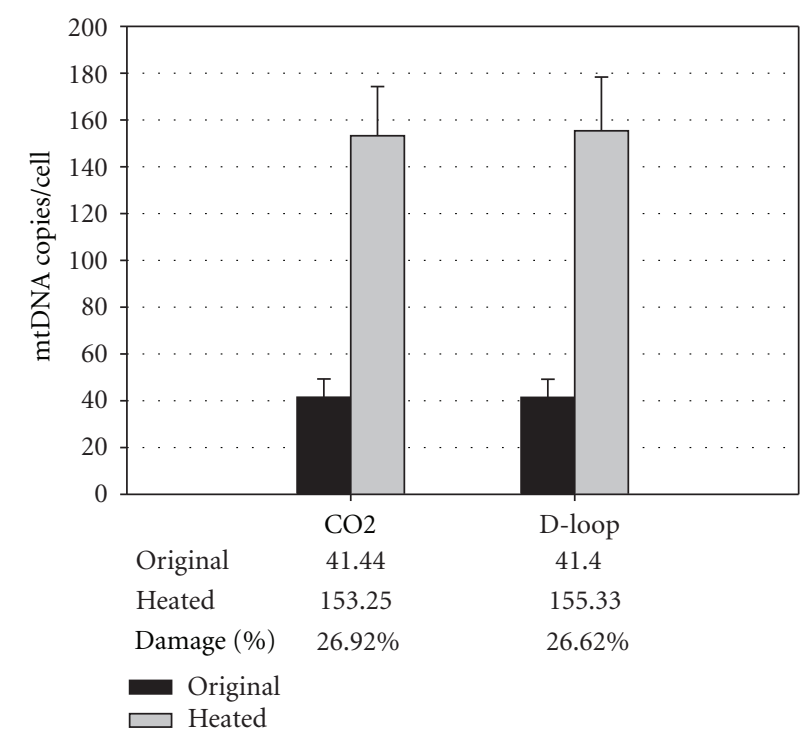

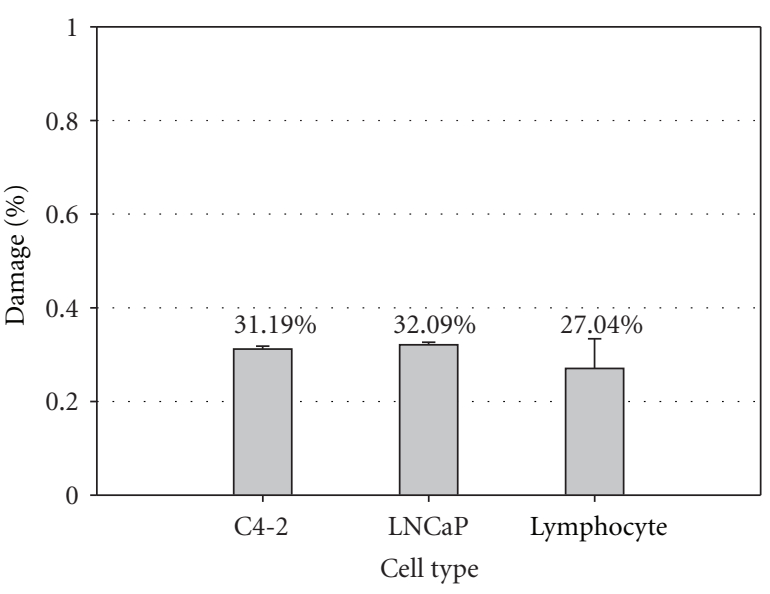

(b)

(c)

FIgURE 3: Absolute quantification of total mtDNA and baseline mtDNA damage in lymphocytes and prostate cancer cells. C4-2 $(n=2)$, LNCaP $(n=2)$, and lymphocytes $(n=4)$ were analyzed by ss-qPCR for total mtDNA content, damaged mtDNA number, and level of baseline damage. The cell number was calculated from the copy numbers of calicin, a single copy nuclear marker. (a) With mtDNA CO2 marker, the original (CO2 original) and preheated (CO2-heated) DNA templates were quantified for damaged copies and total mtDNA copies, respectively. (b) The baseline damage level was obtained by dividing damaged copies over total copies. (c) Comparison of CO2 versus D-loop markers in lymphocyte samples $(n=4)$.

to the isolated lymphocytes in the mtDNA analysis. Thus, mtDNA in blood may be explored as a sensitive surrogate to systemic oxidative stress by simultaneous analysis of multiple end-points in a single test.

The absolute quantification system developed in this study provides a standard method for the reliable quantification of the precise mtDNA copy number in lymphocytes and whole blood cells. This is achieved through well-defined mtDNA and single-copy nuclear DNA markers and by taking into account the DNA structural effects on qPCR amplification [31]. The relatively low mtDNA copy number revealed in isolated lymphocytes is consistent with very limited data reported in the literature. For example, one study detected $\sim 87$ to 579 copies/cell with a different real-time PCR method [36] and the other $\sim 70$ to 320 copies/cell with competitive PCR in lymphocytes [37]. Many studies report mtDNA content on a relative scale $[19,38-41]$. However, the relative analysis is limited by the difficulty of comparing results from one 


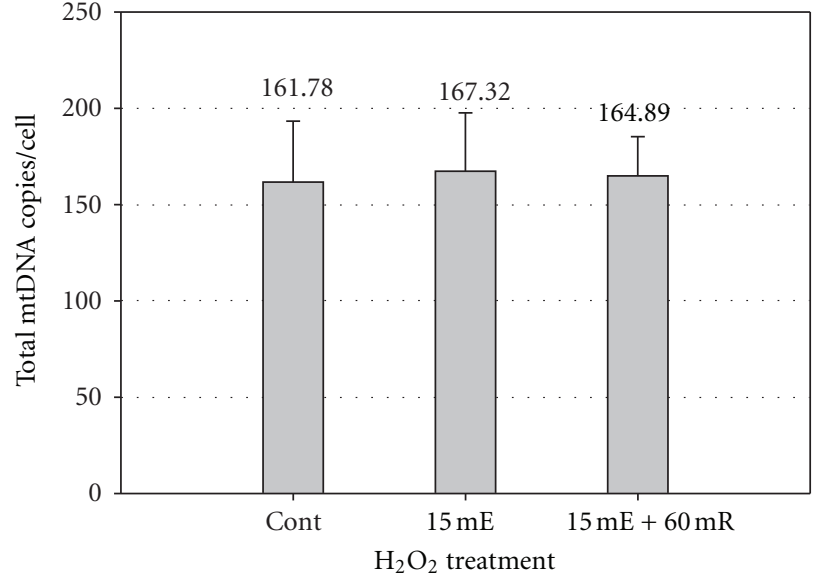

(a)

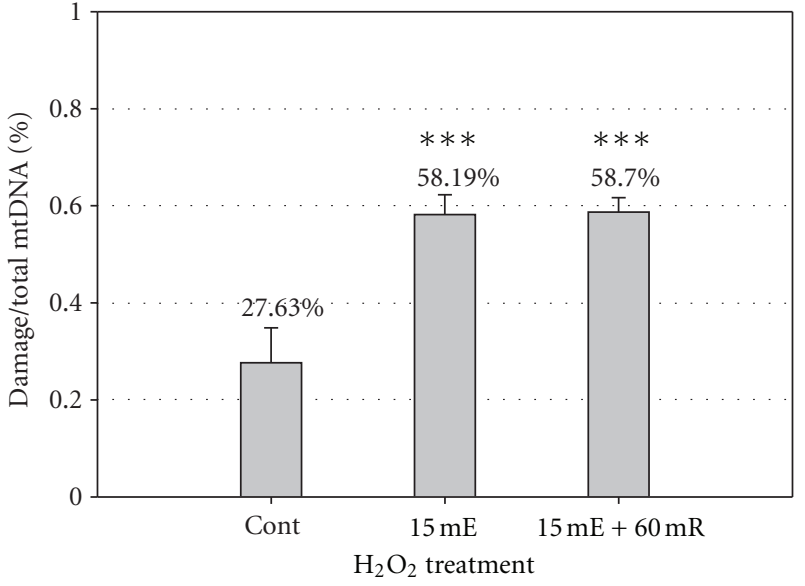

(b)

FIGURE 4: Ex vivo mtDNA damage response to exogenous $\mathrm{H}_{2} \mathrm{O}_{2}$ in isolated lymphocytes and whole blood. Experiments were performed to detect the baseline damage level, induced damage by $\mathrm{H}_{2} \mathrm{O}_{2}$ treatment, and repair capacity of white blood cells from healthy volunteers. Lymphocytes were isolated from fresh blood of three volunteers and stored at $-80^{\circ} \mathrm{C}$. The lymphocytes were split into three groups: untreated control $(n=9), 15 \mathrm{~min}$ of exposure to $120 \mu \mathrm{M} \mathrm{H}_{2} \mathrm{O}_{2}(n=9)$, and 15 min of exposure +60 min recovery $(n=6)$. (a) Total mtDNA content of lymphocytes. (b) MtDNA damage response of lymphocyte samples. $\left({ }^{* * *} P<0.001\right)$.

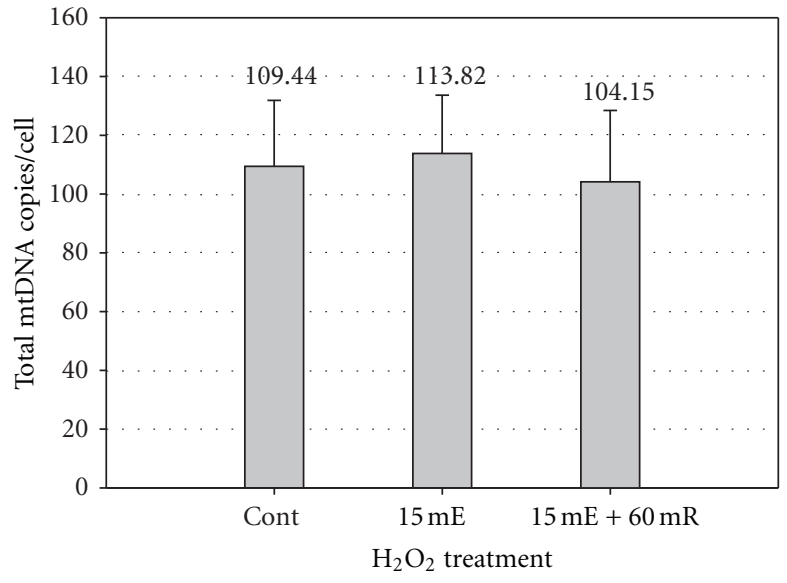

(a)

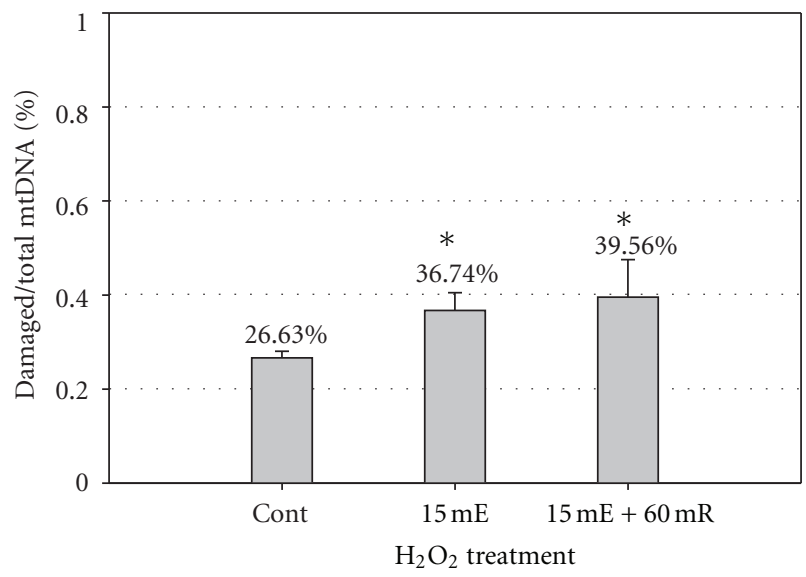

(b)

FIGURE 5: Ex vivo mtDNA damage response to exogenous $\mathrm{H}_{2} \mathrm{O}_{2}$ whole blood. Blood from six healthy male volunteers were collected and stored at $-80^{\circ} \mathrm{C}$. Blood cells from the whole blood samples were separated into three groups in the same manner as lymphocyte samples in Figure 4. (a) Total mtDNA content of whole blood. (b) MtDNA damage response of whole blood. $\left({ }^{*} P<0.05\right)$.

study to another and by the significant variations observed in mtDNA content between individuals [42]. To account for the inhibitory effect of the supercoiled DNA structure on qPCR amplification, we have taken steps to ensure an accurate measurement by disrupting the supercoiled mtDNA conformation with a preheating step prior to $\mathrm{qPCR}$ analysis. This step is necessary for precise quantification of mtDNA content but has largely been ignored in previous reports. Depending on the manufacturers of the qPCR machinery and chemistry kits, there are wide variations in the duration of the initial hot-activation step for hot-start DNA polymerases, which varies from $10 \mathrm{~min}$ to as short as $20 \mathrm{sec}$ (e.g., ABI 7500 Fast System). We have shown that shorter denaturation time at $95^{\circ} \mathrm{C}$ was insufficient to disrupt all the supercoiled mtDNA conformation in a time- and dose-dependent experiment in prostate cancer cell lines [31]. Therefore, the inclusion of a preheating step in the template preparation is crucial for the accurate mtDNA measurement. In addition to measuring the total mtDNA content, our new system also provides a novel approach for direct quantification of the absolute copies of damaged mtDNA with qPCR. This is in contrast to mtDNA conformational study based on gel electrophoresis coupled with Southern Blot, which requires tedious postPCR manipulations and is semiquantitative in nature. On the other hand, popular assays such as the comet test for detecting nuclear DNA strand breaks are not applicable to mtDNA due to its small size [34]. The quantification of structural mtDNA damage reported in this study mainly 
reflects the damage caused by single- and double-stranded breaks, as it was shown that other type of DNA damage such as base lesions or abasic sites had little, if any, effect on the structure [31]. It is interesting to note that the amount of damaged mtDNA changes with the total mtDNA content in a cell. The direct comparison of the damaged mtDNA molecules from different individuals can be compounded by variations in the total content. To normalize this variation, we propose to calculate mtDNA damage based on the percentage of damaged versus total mtDNA molecules in a cell; this ratio of damage is relatively stable and more informative for comparative studies [43]. Moreover, the ratio of damage can be used to infer the baseline or endogenous damage in the isolated lymphocytes or whole blood from the untreated samples; it also quantifies induced mtDNA damage in isolated lymphocytes or a small amount of whole blood cells under oxidative stress. The ability of our approach to measure both endogenous and induced damage/repair responses in ex vivo treatments may be used to explore the state of oxidative defence and/or repair capability of individuals with different disease conditions. Indeed, previous studies have suggested that there is an association between systemic oxidative stress and diseases, such as an association of the high prostate cancer risk with severe damage response and poor repair capacity of nuclear DNA in lymphocytes [14].

In conclusion, we have developed an absolute quantification system for rapid measurement of mtDNA structural damage, copy number change, and damage response in isolated lymphocytes and whole blood cells. Systemic oxidative stress is associated with diverse pathological conditions, ranging from neurodegenerative diseases to many types of cancers. It is conceivable that the blood analysis with the multiple mtDNA end-points proposed in the this study may provide a simple and sensitive test to interrogate the nature and extent of systemic oxidative stress for a broad spectrum of clinical investigations, especially when coupled with other established tests such as cell-free circulating mtDNA, the comet assays targeting the nuclear DNA, and the detection of 8-oxo-G base lesions.

\section{Abbreviations}

mtDNA: Mitochondrial DNA

qPCR: Quantitative real-time polymerase chain reaction 8-oxo-G: 8-oxoguanine

ss-qPCR: Supercoiling-sensitive real-time PCR

SSB: $\quad$ Single-strand breaks

DSB: Double-strand breaks.

\section{Conflict of Interests}

The authors do not have any conflict of interests with the content of the paper.

\section{Acknowledgments}

The authors would like to thank Ms. Y. Han for her comments on an early version of this paper. This work was supported by a Canada Foundation for Innovation Grant (no. 11623) and the McGill Urology Research Funds to J. Z. Chen.

\section{References}

[1] D. C. Wallace, "A mitochondrial paradigm of metabolic and degenerative diseases, aging, and cancer: a dawn for evolutionary medicine," Annual Review of Genetics, vol. 39, pp. 359-407, 2005.

[2] J. Chen and F. Kadlubar, "Mitochondrial mutagenesis and oxidative stress in human prostate cancer," Journal of Environmental Science and Health, vol. 22, no. 1, pp. 1-12, 2004.

[3] C. Richter, "Oxidative damage to mitochondrial DNA and its relationship to ageing," International Journal of Biochemistry and Cell Biology, vol. 27, no. 7, pp. 647-653, 1995.

[4] S. Toyokuni, "Persistent oxidative stress in cancer," FEBS Letters, vol. 358, no. 1, pp. 1-3, 1995.

[5] J. Z. Chen, N. Gokden, G. F. Greene, B. Green, and F. F. Kadlubar, "Simultaneous generation of multiple mitochondrial DNA mutations in human prostate tumors suggests mitochondrial hyper-mutagenesis," Carcinogenesis, vol. 24, no. 9, pp. 1481-1487, 2003.

[6] S. W. Chan, P. N. Nguyen, D. Ayele, S. Chevalier, A. Aprikian, J. Z. Chen et al., "Mitochondrial DNA damage is sensitive to exogenous $\mathrm{H}_{2} \mathrm{O}_{2}$ but independent of cellular ROS production in prostate cancer cells," Mutation Research, vol. 716, no. 1-2, pp. $40-50,2011$.

[7] H. R. Griffiths, "ROS as signalling molecules in T cells ${ }_{2}$ evidence for abnormal redox signalling in the autoimmune disease, rheumatoid arthritis," Redox Report, vol. 10, no. 6, pp. 273-280, 2005.

[8] P. J. Barnes, S. D. Shapiro, and R. A. Pauwels, "Chronic obstructive pulmonary disease: molecular and cellular mechanisms," European Respiratory Journal, vol. 22, no. 4, pp. 672-688, 2003.

[9] G. E. Gibson and H. M. Huang, "Oxidative stress in Alzheimer's disease," Neurobiology of Aging, vol. 26, no. 5, pp. 575-578, 2005.

[10] M. M. Elahi and B. M. Matata, "Functional adaptation to oxidative stress by memory $\mathrm{T}$ cells: an analysis of the role in the cardiovascular disease process," Biochemical and Biophysical Research Communications, vol. 376, no. 3, pp. 445-447, 2008.

[11] C. L. Allen and U. Bayraktutan, "Oxidative stress and its role in the pathogenesis of ischaemic stroke," International Journal of Stroke, vol. 4, no. 6, pp. 461-470, 2009.

[12] A. De Vizcaya-Ruiz, O. Barbier, R. Ruiz-Ramos, and M. E. Cebrian, "Biomarkers of oxidative stress and damage in human populations exposed to arsenic," Mutation Research, vol. 674, no. 1-2, pp. 85-92, 2009.

[13] L. Lavie, L. Dyugovskaya, and A. Polyakov, "Biology of peripheral blood cells in obstructive sleep apnea-he tip of the iceberg," Archives of Physiology and Biochemistry, vol. 114, no. 4, pp. 244-254, 2008.

[14] K. L. Lockett, M. C. Hall, P. E. Clark et al., "DNA damage levels in prostate cancer cases and controls," Carcinogenesis, vol. 27, no. 6, pp. 1187-1193, 2006.

[15] D. J. Waters, S. Shen, H. Xu et al., "Noninvasive prediction of prostatic DNA damage by oxidative stress challenge of peripheral blood lymphocytes," Cancer Epidemiology Biomarkers and Prevention, vol. 16, no. 9, pp. 1906-1910, 2007.

[16] O. Yossepowitch, I. Pinchuk, U. Gur, A. Neumann, D. Lichtenberg, and J. Baniel, "Advanced but not localized prostate cancer 
is associated with increased oxidative stress," Journal of Urology, vol. 178, no. 4, part 1, pp. 1238-1244, 2007.

[17] Q. Wei, L. Cheng, W. K. Hong, and M. R. Spitz, "Reduced DNA repair capacity in lung cancer patients," Cancer Research, vol. 56, no. 18, pp. 4103-4107, 1996.

[18] D. T. Saha, B. J. Davidson, A. Wang, A. J. Pollock, R. A. Orden, and R. Goldman, "Quantification of DNA repair capacity in whole blood of patients with head and neck cancer and healthy donors by comet assay," Mutation Research, vol. 650, no. 1, pp. 55-62, 2008.

[19] J. Xing, M. Chen, C. G. Wood et al., "Mitochondrial DNA content: its genetic heritability and association with renal cell carcinoma," Journal of the National Cancer Institute, vol. 100, no. 15, pp. 1104-1112, 2008.

[20] M. Y. Wu, C. S. Kuo, C. Y. Lin, C. L. Lu, and R. F. Syu Huang, "Lymphocytic mitochondrial DNA deletions, biochemical folate status and hepatocellular carcinoma susceptibility in a case-control study," British Journal of Nutrition, vol. 102, no. 5, pp. 715-721, 2009.

[21] C. Richter, J. W. Park, and B. N. Ames, "Normal oxidative damage to mitochondrial and nuclear DNA is extensive," Proceedings of the National Academy of Sciences of the United States of America, vol. 85, no. 17, pp. 6465-6467, 1988.

[22] P. Mecocci, U. MacGarvey, A. E. Kaufman et al., "Oxidative damage to mitochondrial DNA shows marked age-dependent increases in human brain," Annals of Neurology, vol. 34, no. 4, pp. 609-616, 1993.

[23] M. Hayakawa, T. Ogawa, S. Sugiyama, M. Tanaka, and T. Ozawa, "Massive conversion of guanosine to 8-hydroxyguanosine in mouse liver mitochondrial DNA by administration of azidothymidine," Biochemical and Biophysical Research Communications, vol. 176, no. 1, pp. 87-93, 1991.

[24] G. Colonna-Romano, A. Cossarizza, A. Aquino et al., "Ageand gender-related values of lymphocyte subsets in subjects from Northern and Southern Italy," Archives of Gerontology and Geriatrics, vol. 35, no. 8, pp. 99-107, 2002.

[25] N. Mehra, M. Penning, J. Maas, N. Van Daal, R. H. Giles, and E. E. Voest, "Circulating mitochondrial nucleic acids have prognostic value for survival in patients with advanced prostate cancer," Clinical Cancer Research, vol. 13, no. 2, part 1, pp. 421-426, 2007.

[26] J. Ellinger, S. C. Müller, N. Wernert, A. Von Ruecker, and P. J. Bastian, "Mitochondrial DNA in serum of patients with prostate cancer: a predictor of biochemical recurrence after prostatectomy," BJU International, vol. 102, no. 5, pp. 628-632, 2008.

[27] J. Ellinger, P. Albers, S. C. Müller, A. Von Ruecker, and P. J. Bastian, "Circulating mitochondrial DNA in the serum of patients with testicular germ cell cancer as a novel noninvasive diagnostic biomarker," British Journal of Urology International, vol. 104, no. 1, pp. 48-52, 2009.

[28] C. S. Liu, C. S. Tsai, C. L. Kuo et al., "Oxidative stressrelated alteration of the copy number of mitochondrial DNA in human leukocytes," Free Radical Research, vol. 37, no. 12, pp. 1307-1317, 2003.

[29] C. S. Liu, C. L. Kuo, W. L. Cheng, C. S. Huang, C. F. Lee, and Y. H. Wei, "Alteration of the copy number of mitochondrial DNA in leukocytes of patients with hyperlipidemia," Annals of the New York Academy of Sciences, vol. 1042, pp. 70-75, 2005.

[30] C. M. Chen, Y.-R. Wu, M.-L. Cheng et al., "Increased oxidative damage and mitochondrial abnormalities in the peripheral blood of Huntington's disease patients," Biochemical and Biophysical Research Communications, vol. 359, no. 2, pp. 335-340, 2007.

[31] J. Chen, F. F. Kadlubar, and J. Z. Chen, "DNA supercoiling suppresses real-time PCR: a new approach to the quantification of mitochondrial DNA damage and repair," Nucleic Acids Research, vol. 35, no. 4, pp. 1377-1388, 2007.

[32] H. C. Wu, J. T. Hsieh, M. E. Gleave, N. M. Brown, S. Pathak, and L. W. K. Chung, "Derivation of androgen-independent human LNCaP prostatic cancer cell sublines: role of bone stromal cells," International Journal of Cancer, vol. 57, no. 3, pp. 406-412, 1994.

[33] L. Cheng, L. E. Wang, M. R. Spitz, and Q. Wei, "Cryopreserving whole blood for functional assays using viable lymphocytes in molecular epidemiology studies," Cancer Letters, vol. 166, no. 2, pp. 155-163, 2001.

[34] A. R. Collins, A. A. Oscoz, G. Brunborg et al., "The comet assay: topical issues," Mutagenesis, vol. 23, no. 3, pp. 143-151, 2008.

[35] S. W. Chan and J. Z. Chen, "Measuring mtDNA damage using a supercoiling-sensitive qPCR approach," Methods in Molecular Biology, vol. 554, pp. 183-197, 2009.

[36] M. E. Gahan, F. Miller, S. R. Lewin et al., "Quantification of mitochondrial DNA in peripheral blood mononuclear cells and subcutaneous fat using real-time polymerase chain reaction," Journal of Clinical Virology, vol. 22, no. 3, pp. 241-247, 2001.

[37] A. Cossarizza, M. Pinti, L. Moretti et al., "Mitochondrial functionality and mitochondrial DNA content in lymphocytes of vertically infected human immunodeficiency viruspositive children with highly active antiretroviral therapyrelated lipodystrophy," Journal of Infectious Diseases, vol. 185, no. 3, pp. 299-305, 2002.

[38] J. Shen, M. Platek, A. Mahasneh, C. B. Ambrosone, and H. Zhao, "Mitochondrial copy number and risk of breast cancer: a pilot study," Mitochondrion, vol. 10, no. 1, pp. 62-68, 2010.

[39] G. M. Aldrovandi, C. Chu, W. T. Shearer et al., "Antiretroviral exposure and lymphocyte mtDNA content among uninfected infants of HIV-1-infected women," Pediatrics, vol. 124, no. 6, pp. e1189-e1197, 2009.

[40] S. W. Weng, T.-K. Linb, C.-W. Liou et al., "Peripheral blood mitochondrial DNA content and dysregulation of glucose metabolism," Diabetes Research and Clinical Practice, vol. 83, no. 1, pp. 94-99, 2009.

[41] A. D. D'Souza, N. Parikh, S. M. Kaech, and G. S. Shadel, "Convergence of multiple signaling pathways is required to coordinately up-regulate mtDNA and mitochondrial biogenesis during T cell activation," Mitochondrion, vol. 7, no. 6, pp. 374-385, 2007.

[42] C. T. Moraes, "What regulates mitochondrial DNA copy number in animal cells?" Trends in Genetics, vol. 17, no. 4, pp. 199-205, 2001.

[43] S. Maynard, N. C. de Souza-Pinto, M. Scheibye-Knudsen, and V. A. Bohr, "Mitochondrial base excision repair assays," Methods, vol. 51, no. 4, pp. 416-425, 2010. 


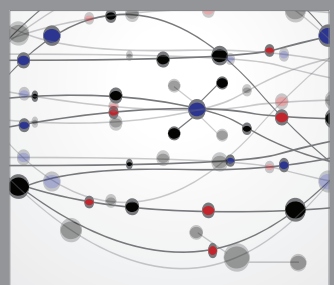

The Scientific World Journal
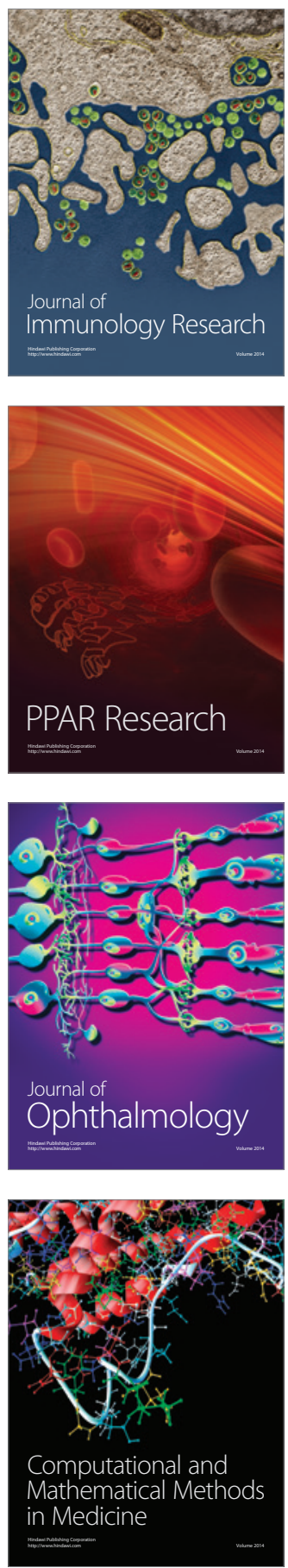

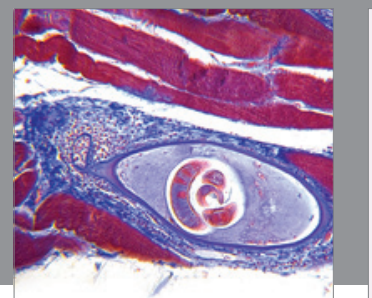

Gastroenterology

Research and Practice
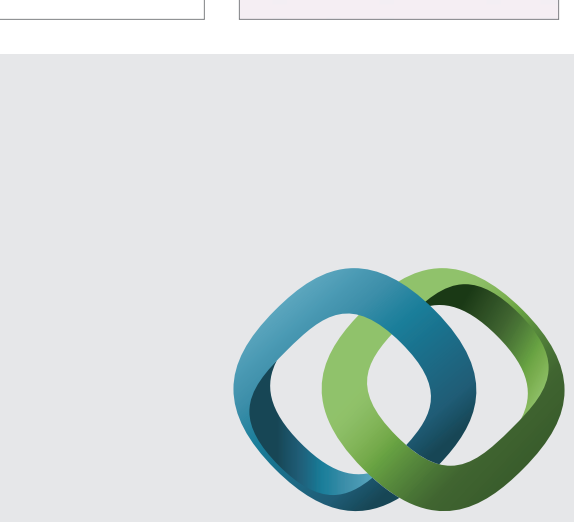

\section{Hindawi}

Submit your manuscripts at

http://www.hindawi.com
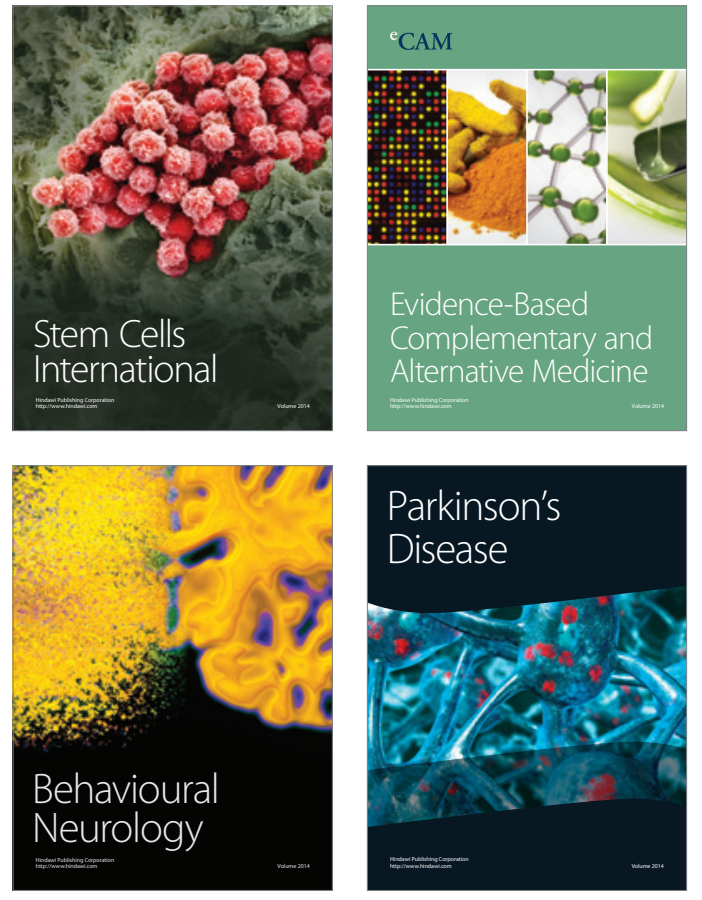
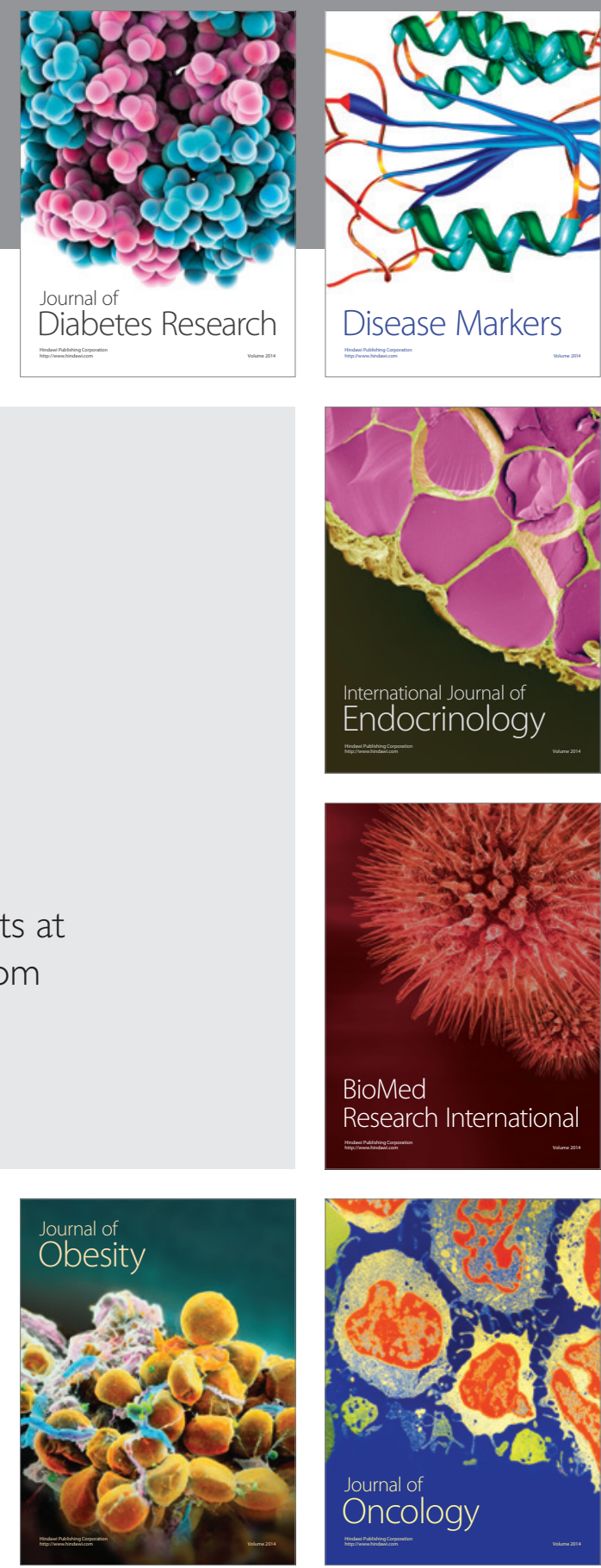

Disease Markers
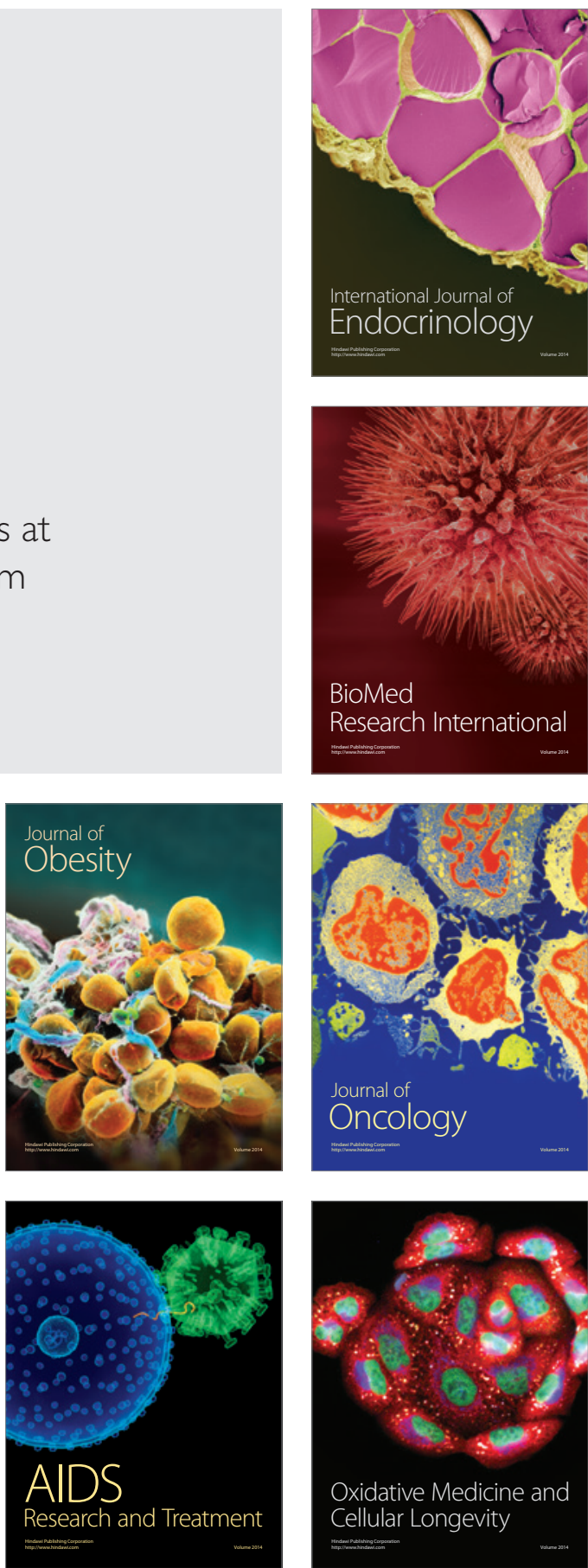